\title{
STUDY OF THE ROLE OF PER-OPERATIVE PERITONEAL LAVAGE WITH SUPER OXIDIZED SOLUTION IN PERFORATION PERITONITIS
}

\author{
Rambabu Meena ${ }^{1}$, Bhagchand Khorwal'2, Anju Meena ${ }^{3}$,Kuldeep Singh Yadav ${ }^{4}$ \\ ${ }_{1}^{1}$ Medical Officer, Department of General Surgery, CHC Mahwa, Dausa. \\ ${ }^{2}$ Medical Officer, Department of General Surgery, CHC Chomu, Jaipur. \\ 3Junior Resident, Department of Anaesthesia, Dr. S. N. Medical College, Jodhpur. \\ ${ }^{4} J$ unior Resident, Department of Psychiatry, MGM College, Jaipur.
}

\begin{abstract}
BACKGROUND

The fundamental in treatment of perforation peritonitis include resuscitation, treatment of septicemia, control of contaminating source and peritoneal toilet. Numerous studies have shown the role of different solutions such as normal saline, antibiotics and betadine as peritoneal lavage in reducing morbidity and mortality of perforation peritonitis. The objective of this study was to present our finding on the role of per-operative peritoneal lavage with super-oxidized solution in cases of perforation peritonitis and its effects on postoperative course and outcome compare to per operative lavage with saline.
\end{abstract}

\section{MATERIALS AND METHODS}

The patients were randomized into two groups. In the control group after the definitive surgery for perforation peritonitis, the peritoneal cavity was lavaged with normal saline and closed after putting drain. In study group after definitive surgery the peritoneal cavity was lavaged with saline followed by $100 \mathrm{ml}$ of super-oxidized solution and drain were closed for $1 \mathrm{~h}$ after abdominal closure. The patients were followed up for morbidity and mortality.

\section{RESULT}

In present study, there was no statistically significance between super-oxidized solution and normal saline lavage group. When we compared it on the basis of postoperative wound infection, fever, burst abdomen and other complication, duration of hospital stay and morbidity and mortality.

\section{CONCLUSION}

By this study we concluded that peritoneal lavage by super-oxidized solution or normal saline alone did not make any difference on patient outcome.

\section{KEYWORDS}

Super-oxidized solution 1; normal saline 2; perforation peritonitis 3.

HOW TO CITE THIS ARTICLE: Meena R, Khorwal B, Meena A, et al. "Study of the role of per-operative peritoneal lavage with superoxidized solution in perforation peritonitis." Journal of Evolution of Medical and Dental Sciences 2015; Vol. 4, Issue 105, December 31; Page: 16988-16990, DOI: 10.14260/jemds/2015/2566

\section{INTRODUCTION}

Perforation peritonitis continues to be a serious problem and in severe instances the fatality rate may be as high as $33 \%$. Clinical outcome may vary from fulminant toxemia to development of sepsis with single or multiple abscesses. The treatment of perforation peritonitis requires early and continuous efforts to control the bacterial factors, colloid changes, cellular and extracellular electrolytes and prevention of respiratory and cardiac failure.

In severe peritonitis, the use of exploratory laparotomy and intraoperative lavage with large amount of saline solution has been the standard of care to reduce risk of postoperative infection. The instillation of crystalloid solutions into the peritoneal cavity during the laparotomy is a routine practice of many surgeons. ${ }^{1}$

Financial or Other, Competing Interest: None.

Submission 05-12-2015, Peer Review 07-12-2015,

Acceptance 18-12-2015, Published 29-12-2015.

Corresponding Author:

Dr. Rambabu Meena,

S/o. Raju Lal Meena,

Vill Ishrikhera Post, Rindli Tel,

Mahwa Dist., Dausa

Raj-321608.

E-mail: rambabumeena25@gmail.com

DOI:10.14260/jemds/2015/2566
A study by Ahrenholz has shown that irrigation with these solutions not only dilute bacterial mass, but also impair bacterial phagocytosis because of dilution of defensive proteins like opsonins. ${ }^{[1][2] ~ S e v e r a l ~ o t h e r ~ s t u d i e s ~ a l s o ~ s u p p o r t ~}$ the idea that intraoperative irrigation with normal saline, in the absence of other antimicrobial substance, have no beneficial effect. $[3,4,5]$ The role of antimicrobial agents such as kanamycin, metronidazole and povidone iodine in Intraoperative Peritoneal Lavage (IOPL) was proved to be non-effective by some authors. [5,6,7]

Recently, some studies have recommended the use of super-oxidized solution with normal saline for irrigation in cases of intra-peritoneal sepsis that it has synergetic effect on patient outcome.[8,9,10,11,12,13] Super-oxidized solutions are neutral $\mathrm{pH}$, hypotonic solutions with a controlled amount of reactive species and low chlorine content. Its antiseptic properties are due to its reactive species of oxygen and chlorine. These reactive species create an unbalanced osmolarity, so that it damages the integrity of the cell membrane, then react and denature the lipids and proteins of single cell organisms. This is because of a direct result of the osmolarity difference between the ion concentrations of the solution and single cell organisms. 
Multicellular organisms are not prone to such osmolarity changes, therefore host tissues are spared.

Super-oxidized solutions have been used in humans for cleansing of ulcers, mediastinal irrigation, peritoneal lavage and hand washing. This study was conducted to evaluate the role of super-oxidized solution and normal saline in cases of peritonitis. $[14,15,16]$

\section{MATERIALS AND METHODS}

This study was conducted on patients who had exploratory laparotomy for perforation peritonitis at MBS Hospital, Kota, from 2011 to 2013. Seventy five patients were included in this study. These cases were randomized in the control group and study group.

Only those patients who were found to have perforation peritonitis on exploratory laparotomy were included in the study. Patients with evidence of enteric encephalopathy, liver diseases, renal diseases, history of steroid intake, heart disease and known allergy to any substance with diagnosis of perforation peritonitis were excluded from the study.

All the patients were resuscitated to make vitally stable for surgery and commenced on broad spectrum intravenous antibiotic covering gram positive, gram negative and anaerobes which were continued for reasonable postoperative period. All patients received same preoperative and postoperative antibiotic to eliminate antibiotic associated bias Foleys catheterization and nasogastric aspiration tube insertion was done whenever it was necessary. All routine blood and radiological investigations were done. At the time of operation, site, size and number of perforations were noted. Any other associated pathology was noted. Operative procedure was carried out.

After the definitive surgery, patients were randomly put into two groups control group and study group. In control group, after doing definitive surgery for pathology the peritoneal cavity was washed with 3-4 L of saline. Then the abdominal cavity was closed after putting drains. In the study group, after definitive surgery for pathology, the peritoneal cavity was washed with 3-4 L of saline. Then $100 \mathrm{ml}$ of superoxidized solution was put in the peritoneal cavity and the abdomen was closed after putting drains. The drains were clamped for $1 \mathrm{~h}$, so that the super-oxidized solution did not escape. (SOS group).

In postoperative period, the primary dressing was removed after $48 \mathrm{~h}$ and daily dressing was carried out with povidone-iodine solution. The wound was inspected for signs of infection (sinus formation, seroma formation and pus formation) and dehiscence before each dressing. Drain output was monitored daily, amount and also its character (serous/purulent). Fever was also noted. The drains were removed when output was $<50 \mathrm{ml}$ daily and serous. Day of drain removal was noted.

\section{RESULTS}

\begin{tabular}{|c|c|c|c|}
\hline Factor & $\begin{array}{c}\text { No. of Cases in } \\
\text { NS } \\
\text { Lavage Group }\end{array}$ & $\begin{array}{c}\text { No. of Cases in SOS } \\
\text { Lavage Group }\end{array}$ & Total \\
\hline $18-30$ & $16(50 \%)$ & $16(50 \%)$ & 32 \\
\hline $31-40$ & $7(50 \%)$ & $7(50 \%)$ & 14 \\
\hline $41-50$ & $6(54.5 \%)$ & $5(45.4 \%)$ & 11 \\
\hline
\end{tabular}

\begin{tabular}{|c|c|c|c|}
\hline $51-60$ & $5(50 \%)$ & $5(50 \%)$ & 10 \\
\hline$>60$ & $6(75 \%)$ & $2(25 \%)$ & 8 \\
\hline Total & $\mathbf{4 0}$ & $\mathbf{3 5}$ & $\mathbf{7 5}$ \\
\hline \multicolumn{3}{|c|}{ Table 1: Distribution of Demographic Factor } \\
\hline
\end{tabular}

\begin{tabular}{|c|c|c|c|}
\hline Gender & $\begin{array}{c}\text { No. of Cases in NS } \\
\text { Lavage Group }\end{array}$ & $\begin{array}{c}\text { No. of Cases in SOS } \\
\text { Lavage Group }\end{array}$ & Total \\
\hline Male & $35(60.3 \%)$ & $33(57 \%)$ & 58 \\
\hline Female & $11(64.7 \%)$ & $6(35.3 \%)$ & 17 \\
\hline Total & $\mathbf{4 6}$ & $\mathbf{3 9}$ & $\mathbf{7 5}$ \\
\hline \multicolumn{3}{|c|}{ Table 2: Distribution of Age } \\
\hline
\end{tabular}

\begin{tabular}{|c|c|c|c|}
\hline Causes & $\begin{array}{c}\text { No. of Cases in NS } \\
\text { Lavage Group }\end{array}$ & $\begin{array}{c}\text { No. of Cases in } \\
\text { SoS Lavage Group }\end{array}$ & Total \\
\hline Peptic & $19(45.2 \%)$ & $16(48.5 \%)$ & 35 \\
\hline Appendicular & 0 & $1(0.03 \%)$ & 1 \\
\hline Enteric & $15(35.8 \%)$ & $9(27.3 \%)$ & 24 \\
\hline Traumatic & $7(16.7 \%)$ & $6(18.2 \%)$ & 13 \\
\hline Colonic & $1(0.02 \%)$ & $1(0.03 \%)$ & 2 \\
\hline Total & 42 & 33 & 75 \\
\hline \multicolumn{4}{|c|}{ Table 3: Causes of Perforation } \\
\hline
\end{tabular}

\begin{tabular}{|c|c|c|}
\hline Complications & $\begin{array}{l}\text { No. of Cases in NS } \\
\text { Lavage Group }\end{array}$ & $\begin{array}{c}\text { No. of Cases in SOS } \\
\text { Lavage Group }\end{array}$ \\
\hline Fever & $40(95.2 \%)$ & $33(100 \%)$ \\
\hline Wound complication & $24(57.1 \%)$ & $19(57.6 \%)$ \\
\hline $\begin{array}{c}\text { Requirement of } \\
\text { higher antibiotics }\end{array}$ & $20(47.6 \%)$ & $19(57.6 \%)$ \\
\hline $\begin{array}{l}\text { Intra-abdominal } \\
\text { sepsis or leak }\end{array}$ & $6(14.3 \%)$ & $2(0.06 \%)$ \\
\hline Mortality & $8(19 \%)$ & $1(0.03 \%)$ \\
\hline \multicolumn{3}{|c|}{ Table 4: Incidence of Postoperative Complication } \\
\hline
\end{tabular}

\section{DISCUSSION}

The present clinical study is an attempt to improve the clinical outcome without inducing chemical related toxicity to the peritoneum by intra-operative peritoneal lavage with a neutral $\mathrm{pH}$ solution with a controlled amount of reactive species and low chronic content $(<70 \mathrm{ppm})$ is evaluated to know its effect on postoperative course and outcome in cases of perforation peritonitis.

The present study comprises of a comparative clinical study of 75 cases of perforation peritonitis treated by intraoperative peritoneal lavage with super oxidized solution and the results were compared with control group in which only saline was used for intraoperative peritoneal lavage.

Most common type of perforation was peptic followed by enteric in both groups. So, both groups are comparable on the bases of the type of perforation. These findings are also comparable with various studies.[17,18,19,20.21] Peptic perforation is more common in older age group of 51-60 yrs $(11 / 35$ cases) while enteric perforation is more common in younger patients $18-30$ yrs $(17 / 24$ cases $)$ most of the traumatic perforations were seen between 18-40 years of age.

In present study 73 out of 75 patients had fever, which was controlled by antipyretic and antibiotic; 43 out of 75 patients had wound infection were cured by regular dressing and 
antibiotics; 39 out of 75 patients had required higher antibiotic due to complication. In present study, the overall mortality was 9 out of 75 patients (12\%). They were fully recovered from surgical stress, but died because of severe peritonitis septicemia in older age patients with their delayed presentation; 8 out of 75 patients had developed intraabdominal sepsis that was cured by IV higher antibiotics. No toxic effects were seen with the use of super oxidized solution intra-peritoneally for lavage.

CONCLUSION: To conclude, in this present study the use of intra-operative peritoneal lavage with SOS show some beneficial effect as far as early return of bowel sound and duration of hospital stay is concerned, but there is no much difference in improving the post-operative course and outcome as far as incidence of post-operative fever, wound infection, requirement of higher antibiotics are concerned. More studies are required to establish the role of intraoperative peritoneal lavage with super oxidized solution as a standard procedure for intra operative peritoneal lavage in cases of perforation peritonitis.

\section{REFERENCES}

1. Lally KP, Nichols RL. Various intraperitoneal irrigation solutions in treating experimental fecal peritonitis. South Med J 1981;74:789-91, 798.

2. Ahrenholz DH. Effect of intraperitoneal fluid on mortality of Escherichia coli peritonitis. Surg Forum 1979;30:483-4.

3. Rakower SR, Keyes J, Miethaner WL. The protective role of intraperitoneal antibiotic irrigation in contaminated penetrating wounds of the cecum. Surgery 1976; 80:40510.

4. Keating JP, Neill M, Hill GL. Sclerosing encapsulating peritonitis after intraperitoneal use of povidone iodine. Aust N Z J Surg 1997; 67:742-4.

5. Khan SM, Verma AK, Shahid M, et al. Evaluation of preoperative peritoneal lavage by super-oxidized solution in peritonitis. Middle East J Intern Med 2009; 3:15-35.

6. Inoue $\mathrm{Y}$, Endo S, Kondo K, Ito H, Omori H, Saito K. Trial of electrolyzed strong acid aqueous solution lavage in the treatment of peritonitis and intraperitoneal abscess. Artif Organs 1997; 21:28-31.
7. Noon GP, Beall AC, Jordan GL, et al. Clinical evaluation of peritoneal irrigation with antibiotic solution. Surg 1967;62:73-8.

8. Fowler R. A controlled trial of intraperitoneal cephaloridine administration in peritonitis. J Pediatr Surg 1975;10:43-50.

9. Stewart DJ, Matheson NA. Peritoneal lavage in appendicular peritonitis. Br J Surg 1978;65:54-6.

10. Nomikos IN, Katsouyanni K, Papaioannou AN. Washing with or without chloramphenicol in the treatment of peritonitis: A prospective, clinical trial. Surgery 1986;99:20-5.

11. Khanna AK, Misra MK. Typhoid perforation of the gut. Postgrad Med J 1984;60:523-5.

12. Vallance S, Waldron R. Antiseptic vs. saline lavage in purulent and faecal peritonitis. J Hosp Infect 1985;6(Suppl A):87-91.

13. Bhushan C, Mital VK, Elhence IP. Continuous postoperative peritoneal lavage in diffuse peritonitis using balanced saline antibiotic solution. Int Surg 1975;60:526-8.

14. Sekiya S, Ohmori K, Harii K. Treatment of infectious skin defects or ulcers with electrolyzed strong acid aqueous solution. Artif Organs 1997;21:32-8.

15. Ohno H, Higashidate M, Yokosuka T. Mediastinal irrigation with super-oxidized water after open-heart surgery: The safety and pitfalls of cardiovascular surgical application. Surg Today 2000;30:1055-6.

16. Sakashita M, Iwasawa A, Nakamura Y. Antimicrobial effects and efficacy on habitually hand-washing of strong acidic electrolyzed water - A comparative study of alcoholic antiseptics and soap and tap water. Kansenshogaku Zasshi 2002; 76:373-7.

17. Bhansali SK. Gastrointestinal perforations. A clinical study of 96 cases. J Postgrad Med 1967; 13:1-12.

18. Sharma L, Gupta S, Soin AS, et al. Generalized peritonitis in India - The tropical spectrum. Jpn J Surg 1991; 21:272-7.

19. Dorairajan LN, Gupta S, Deo SV, et al. Peritonitis in India A decade's experience. Trop Gastroenterol 1995; 16:33-8.

20. Alam A, Ashraf SM, Malik A. A study of gastrointestinal tract perforation (non-traumatic). MS Thesis. AMU Aligarh; 1992.

21. Desa LA, Mehta SJ, Nadkarni KM, et al. Peritonitis: A study of factor contributing to mortality. Ind J Surg 1983; 45:593. 